\title{
ON SHAFER-FINK INEQUALITIES
}

\author{
LING ZHU
}

Abstract. In this paper, a new upper bound for inverse sine is established.We would point out that the numbers, 3 and $\pi, 6$ and $\pi\left(\sqrt{2}+\frac{1}{2}\right)$, in Shafer-Fink inequalities, are optimal.

Mathematics subject classification (2000): 26D15.

Key words and phrases: inverse sine; upper and lower bounds; Shafer-Fink inequalities.

\section{REFERENCES}

[1] D. S. Mitrinović, Analytic Inequalities, Springer-Verlag, 1970.

[2] A. M. FinK, Two Inequalities, Univ.Beograd.Publ.Elektrotehn.Fak., 6, (1995), 49-50. 